\title{
INDICADORES REPRODUCTIVOS EN DOS POBLACIONES NATURALES DE Pinus hartwegii LINDL
}

\author{
REPRODUCTIVE INDICATORS IN TWO NATURAL \\ POPULATIONS OF Pinus hartwegii LINDL
}

\author{
Karem A. Andrade-Gómez', Carlos Ramírez-Herrera ${ }^{1 *}$, Javier López- \\ Upton', Marcos Jiménez-Casas ${ }^{1}$ y Ricardo Lobato-Ortiz ${ }^{2}$
}

\author{
${ }^{1}$ Colegio de Postgraduados (CP), Posgrado en Ciencias Forestales, Montecillo, Texcoco, Estado de México, México. ${ }^{2} \mathrm{CP}$, Posgrado de Recursos \\ Genéticos y Productividad, Montecillo, Texcoco, Estado de México, México. \\ *Autor de correspondencia (kmcramcolpos@gmail.com)
}

\section{RESUMEN}

Pinus hartwegii Lindl. crece entre 2500 y 4300 msnm en las montañas de México y América Central. Información sobre indicadores reproductivos en una población es útil para describir el estado reproductivo de una especie y éstos pueden estar influenciados por variables ambientales. El objetivo del presente estudio fue evaluar la variación de indicadores reproductivos entre altitudes en poblaciones de Pinus hartwegii. Los conos se recolectaron entre 3600 y 4100 msnm en el Monte Tláloc (MT) y el Nevado de Toluca (NT) en México. En cada cono se determinó el número de semillas potenciales (NSP), óvulos abortados en el año 1 (NOAA1), óvulos abortados en el año 2 (NOAA2), semillas vanas (NSV), semillas llenas (NSLL), peso promedio de una semilla (PPS), eficiencia reproductiva (ER), eficiencia en la producción de semillas (EPS) e índice de depresión endogámica (IDE). Las variables ambientales se obtuvieron con el programa Spline. Los coeficientes de correlación (r) se calcularon entre indicadores reproductivos y variables ambientales. Se encontraron diferencias significativas entre poblaciones y entre altitudes en NSP, NOAA2, NSV, NSLL, PPS y ER, mientras que no hubo diferencias significativas entre poblaciones para EPS e IDE, aunque sí entre altitudes; tampoco se encontraron diferencias significativas entre poblaciones ni entre altitudes para NOAA1. El coeficiente de correlación fue alto $(r=0.929)$ entre NOAA2 y precipitación en septiembre y octubre; también éste fue alto $(r=-0.829)$ entre ER y heladas tardías en primavera. Algunos valores de $r$ fueron moderados entre indicadores reproductivos y variables ambientales; por ejemplo, el coeficiente de correlación fue 0.786 entre NSV y temperatura media anual, de 0.714 entre el NSLL y temperatura máxima media del mes más caliente y $r=-0.642$ entre NSP y temperatura media mínima del mes más frio. Los valores de los indicadores reproductivos mostraron variación entre las poblaciones y entre altitudes dentro de poblaciones de Pinus hartwegii.

Palabras clave: Pinus hartwegii, depresión endogámica, eficiencia reproductiva, semillas potenciales.

\section{SUMMARY}

Pinus hartwegii Lindl. grows between 2500 and 4300 masl in the mountains of Mexico and Central America. Information on reproductive indicators in a population is useful to describe the reproductive status of a species, and may be influenced by environmental variables. The objective of this study was to evaluate the variation of reproductive indicators between altitudes in Pinus hartwegii populations. Cones were collected between 3600 and 4100 masl at Monte Tlaloc (MT) and Nevado de Toluca (NT) in Mexico. The number of potential seeds (NPS), aborted ovules in year 1 (AOY1), aborted ovules in year 2 (AOY2), empty seeds (ES), full seeds (FS), mean weight of a seed (MWS), reproductive efficiency (RE), efficiency in seed production (ESP) and endogamy depression index (EDI) were determined in each cone. The environmental variables were obtained with the Spline program. Correlation coefficients $(r)$ were estimated between reproductive indicators and environmental variables. Significant differences were found between populations and between altitudes within populations for NPS, AOY2, ES, FS MWS and RE, while there were no significant differences between populations for ESP and EDI, they were present between altitudes; neither were significant differences between populations and altitudes for AOY1. The correlation coefficient was high $(r=0.929)$ between AOY2 and precipitation in September and October; it was also high $(r=-0.829)$ between RE and late frosts in Spring Some $r$ values between reproductive indicators and environmental variables were moderate; for example, the correlation coefficient was 0.786 between NSV and mean annual temperature, it was 0.714 between NSLL and mean maximum temperature of the warmest month, while it was -0.642 between NPS and mean minimum temperature in the coldest month. The values of reproductive indicators showed variation between populations and between altitudes within Pinus hartwegii populations.

Index words: Pinus hartwegii, inbreeding depression, potential seeds, reproductive efficiency,

\section{INTRODUCCIÓN}

Pinus hartwegii Lindl. es una especie que se distribuye entre 2500 y 4300 msnm en México y América Central, donde las temperaturas bajo cero son comunes en invierno; los árboles de esta especie pueden alcanzar alturas superiores a los $30 \mathrm{~m}$ y diámetros normales mayores a 1 m (Perry, 1991). En el Monte Tláloc P. hartwegii se localiza a una altitud de 3500 a 4100 m, mientras que en el Nevado de Toluca, esta especie habita entre 3600 y 4200 m.

Actualmente, la información sobre la situación de los bosques de Pinus hartwegii es escasa, aunque se menciona que las actividades extractivas, incendios y plagas han reducido y fragmentado las poblaciones de esta especie en el Eje Neovolcánico (Endara-Agramont et al., 2013) También, la disminución de la precipitación y aumento 
de la temperatura pueden ser causas de la reducción de la superficie cubierta por P. hartwegii (Astudillo-Sánchez et al., 2017). Existen proyecciones de que los bosques de esta especie pueden tener una disminución del 49 \% con respecto al área que actualmente ocupan como consecuencia del cambio climático (Villers-Ruiz y Trejovázquez, 2004).

La distancia de dispersión de las semillas P. hartwegii se desconoce; sin embargo, en la mayoría de las ocasiones, las semillas se mueven a distancias menores a $10 \mathrm{~m}$ del árbol dispersor, agrupando y promoviendo el cruzamiento entre árboles emparentados (Burczyka et al., 2004). Un número reducido de árboles en edad reproductiva y emparentados puede incrementar la probabilidad de endogamia, lo que acelera la pérdida de poblaciones por la acción de genes deletéreos al formar genotipos homocigóticos (Hartl y Clark, 2007), lo que provoca depresión endogámica y muerte de los embriones durante su desarrollo y como consecuencia se producen semillas vanas (Owens et al., 2005). La variabilidad en caracteres reproductivos puede estar influenciada por la calidad de los sitios y condiciones microambientales (White et al., 2007). Información sobre características reproductivas es útil para comprender los procesos genéticos en una población y monitorear la viabilidad de poblaciones (Rajora et al., 2000), por lo que el análisis de conos y semillas es una herramienta útil para conocer el estado reproductivo de las coníferas (Owens et al., 2005). Diversas variables ambientales como precipitación, temperatura altitud y factores genéticos de los árboles influyen en la reproducción de individuos de una especie (White et al., 2007). Las condiciones ambientales pueden influir en las características reproductivas de los árboles de esta especie por lo que se esperan diferencias entre los indicadores reproductivos entre poblaciones y altitudes dentro de poblaciones de P. hartwegii. Bajo este contexto el objetivo del presente estudio fue evaluar los indicadores reproductivos de árboles de dos poblaciones de Pinus hartwegii en diferentes altitudes en México.

\section{MATERIALES Y MÉTODOS}

\section{Origen de las poblaciones}

Ambas poblaciones de Pinus hartwegii se localizan en el Eje Neovolcánico, una en el Monte Tláloc (MT), Texcoco, al oriente del Estado de México, entre las coordenadas geográficas 19² 23' 52.85" N, $98^{\circ}$ 43' 57.81" O a 3600 msnm y $19^{\circ} 24^{\prime} 46.95^{\prime \prime} \mathrm{N}, 98^{\circ} 43^{\prime} 10.45^{\prime \prime} \mathrm{O}$ a 4000 msnm; la otra se sitúa en el Volcán Nevado de Toluca (NT), Zinacantepec, Estado de México, entre las coordenadas geográficas $19^{\circ}$ $07^{\prime} 46.1^{\prime \prime} \mathrm{N}, 99^{\circ} 46^{\prime} 50.35^{\prime \prime} \mathrm{O}$ a 3,900 msnm y 19 07' 17.57" N, $99^{\circ} 45^{\prime} 10.76^{\prime \prime}$ O a 4100 msnm (Figura 1).
En el Monte Tláloc se recolectaron 214, 284, 124 y 18 estróbilos de 30 árboles en los niveles altitudinales 3600, 3700, 3800 y 4000 msnm, respectivamente, mientras que en el Nevado de Toluca se recolectaron 33, 45 y 314 estróbilos de 20 árboles en las altitudes 3900, 4000 y 4100 msnm, respectivamente. La selección de los árboles se realizó con base en la presencia de estróbilos y ausencia de ataque de plagas. Se asignó un número a cada árbol con base en el orden de selección. Los conos de cada árbol se colocaron en bolsas de manta para su transporte. Cada bolsa se marcó con el nombre de la población, la altitud y número de árbol. En el laboratorio, se colocó cada cono en una bolsa de papel de estraza y se identificó con el nombre de la población, número de árbol y se asignó un número al cono.

\section{Procesamiento de las muestras y registro de variables}

Los conos se mantuvieron en las bolsas a temperatura ambiente por una semana para promover la pérdida de humedad, y posteriormente se movieron a un invernadero por 24 horas para completar la apertura de las escamas. Se contaron las escamas fértiles, se golpearon los conos sobre una mesa para extraer las semillas; posteriormente, se removió cada escama con un gancho de metal para liberar del cono la totalidad de las semillas. Cada cono se colocó a una temperatura de $109{ }^{\circ} \mathrm{C}$ por 24 horas en un horno eléctrico de secado de circulación forzada (Riossa ${ }^{\circledR}$ Modelo H-62, RSU Instruments, México). Pasadas las 24 h, se pesaron los conos secos en una balanza analítica digital (Chyo ${ }^{\circledR}$ Modelo JK-200, Crescent, Singapur); enseguida, se eliminaron impurezas y las alas de las semillas y se contó el número de semillas desarrolladas y de óvulos abortados en el año 2. Se consideró como óvulo abortado en el año 2 a la estructura con testa arrugada, podrida y de tamaño menor al de una semilla desarrollada (Bramlett et al., 1977). El número de semillas potenciales es el número de escamas fértiles multiplicado por 2 (Bramlett et al., 1977). Se estimó el número de óvulos abortados en el año 1 como la diferencia entre el número de semillas potenciales y el número de óvulos abortados en el año 2 y número de semillas desarrolladas (Bramlett et al., 1977). Después, se clasificaron las semillas dañadas como las semillas desarrolladas que presentaron evidencias de daño mecánico o daño por insectos.

Las semillas restantes se colocaron en una columna de aire para separar las semillas vanas de las llenas. Una semilla llena tiene un embrión y megagemetofito cubiertos por la nucela y testa. Las semillas que flotaron se consideraron como semillas vanas. Se registró el número de semillas Ilenas y semillas vanas; las semillas llenas se pesaron en una balanza analítica digital (Chyo ${ }^{\circledR}$ 


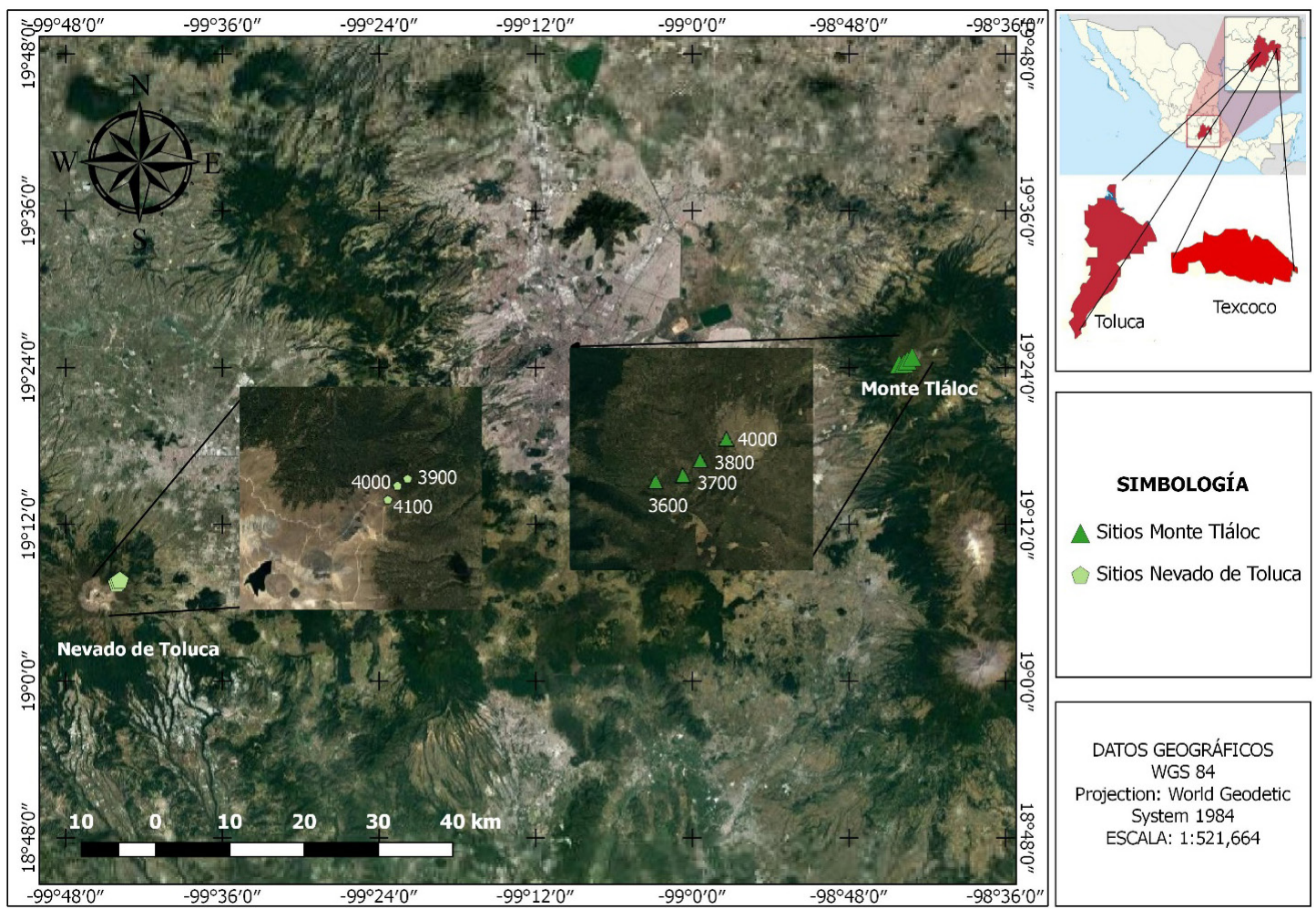

Figura 1. Ubicación de los sitios de Pinus hartwegii a diferentes altitudes en el Monte Tláloc y Nevado de Toluca, Estado de México.

Mod. JK-200, Crescent, Singapur). Se calculó el peso promedio de una semilla como la división del peso de las semillas entre el número de semillas llenas de cada cono. Se utilizó el peso promedio de una semilla para estimar el número de semillas en $1 \mathrm{~kg}$. La relación entre el peso de la semilla llena por cono y el peso seco del cono dio como resultado la eficiencia reproductiva (Mosseler et al., 2000). La eficiencia en la producción de semilla es la relación entre el total de semillas llenas y el número de semillas potenciales (Bramlett et al., 1977). Se calculó el índice de depresión endogámica, el cual se definió como el total de semillas vanas entre el total de semillas desarrolladas bajo el supuesto de que las semillas vanas son resultado de la acción de genes deletéreos en estado homocigótico (Mosseler et al., 2000). Se hizo la comparación de los resultados de cada variable con el porcentaje, el cual se calculó como la diferencia entre el valor mayor y menor, dividido entre el valor menor de cada indicador reproductivo.

\section{Variables ambientales}

Las variables ambientales se obtuvieron con el programa Spline Model (Rehfeldt, 2006), para las altitudes en donde se recolectaron los estróbilos dentro de cada población (Cuadro 1).

\section{Análisis estadístico}

Los datos de cada una de las variables se sometieron a las pruebas de Shapiro-Wilk y de Bartlett para verificar los supuestos de normalidad y homogeneidad de varianzas, respectivamente, con los procedimientos UNIVARIATE y GLM utilizando el software SAS/PC para Windows versión 9.4 (SAS Institute, 2012). Cuando las variables cumplieron con los supuestos de normalidad y homogeneidad de varianzas, se realizó un análisis de varianza con el procedimiento GLIMMIX-SAS/PC para Windows versión 9.4 (SAS Institute, 2012) con el modelo:

$$
Y_{i j k}=\mu+P_{i}+A_{j(i)}+\varepsilon_{i j k}
$$

donde: $Y_{i j k}$ es la $k$ observación en la j-ésimo altitud en la i-ésima población, $\mu$ es la media poblacional, $P_{i}$ es la i-ésima población, $A_{j(i)}$ es la j-ésima altitud dentro de la i-ésima población y $\varepsilon_{i j k}$ es el error aleatorio.

Se obtuvieron las pruebas de medias mediante el procedimiento LSMEANS-SAS/PC para Windows versión 9.4 (SAS Institute, 2012). Semillas vanas, óvulos abortados en el año 2 e índice de endogamia no cumplieron con los supuestos de normalidad y homogeneidad de varianzas, por lo que se analizaron con una prueba Kruskal-Wallis 
Cuadro 1. Variables ambientales en diferentes altitudes en el Monte Tláloc y Nevado de Toluca.

\begin{tabular}{|c|c|c|c|c|c|c|c|}
\hline \multirow[t]{2}{*}{ Variables ambientales } & \multicolumn{4}{|c|}{$\begin{array}{l}\text { Monte Tláloc } \\
\text { Altitud (msnm) }\end{array}$} & \multicolumn{3}{|c|}{$\begin{array}{l}\text { Nevado de Toluca } \\
\text { Altitud (msnm) }\end{array}$} \\
\hline & 3600 & 3700 & 3800 & 4000 & 3900 & 4000 & 4100 \\
\hline Precipitación media anual (mm) & 1149 & 1182 & 1218 & 1288 & 1179 & 1195 & 1210 \\
\hline Precipitación en abril y mayo (mm) & 162 & 166 & 169 & 177 & 160 & 164 & 168 \\
\hline Precipitación en julio y agosto (mm) & 445 & 457 & 468 & 488 & 436 & 444 & 454 \\
\hline Precipitación en septiembre y octubre (mm) & 478 & 493 & 509 & 543 & 507 & 512 & 616 \\
\hline Precipitación de noviembre a febrero (mm) & 64 & 66 & 72 & 80 & 76 & 75 & 72 \\
\hline Temperatura media anual $\left({ }^{\circ} \mathrm{C}\right)$ & 7.2 & 6.7 & 6.1 & 5.0 & 5.6 & 4.9 & 4.2 \\
\hline Temperatura media mín. en el mes más frío $\left({ }^{\circ} \mathrm{C}\right)$ & -1.4 & -1.6 & -1.8 & -2.2 & -0.7 & -1 & -1.5 \\
\hline Temperatura media máx. mes más caliente $\left({ }^{\circ} \mathrm{C}\right)$ & 16.0 & 15.2 & 14.5 & 13.0 & 12.3 & 11.4 & 10.3 \\
\hline Longitud del periodo de heladas (días) & 108 & 106 & 102 & 89 & 110 & 103 & 95 \\
\hline NDAUHP & 154 & 157 & 157 & 162 & 153 & 158 & 161 \\
\hline NDAPHO & 216 & 259 & 258 & 255 & 260 & 259 & 255 \\
\hline
\end{tabular}

NDAUHP. número del día en el año Juliano de última helada en primavera, NDAPHO: número del día en el año Juliano de la primera helada en primavera.

con el procedimiento NPARTWAY-SAS/PC para Windows versión 9.4 (SAS Institute, 2012). Se calculó el coeficiente de correlación de Spearman entre los indicadores reproductivos y las variables ambientales.

\section{RESULTADOS Y DISCUSIÓN}

\section{Semillas potenciales}

Existieron diferencias significativas $(P \leq 0.0001)$ entre poblaciones y entre altitudes dentro de poblaciones de $P$. hartwegii para el número de semillas potenciales. Los valores promedio fueron 170 y 209 semillas potenciales en el Nevado de Toluca y Monte Tláloc, respectivamente. El número de semillas potenciales fue $12.7 \%$ mayor en la altitud de 3800 msnm con respecto al valor que se registró en la altitud de 3700 msnm en el MT, mientras que esta variable fue $13 \%$ mayor en la altitud 3900 msnm con respecto al valor en la altitud 4100 msnm en el NT (Cuadro 2).

El valor promedio del número de semillas potenciales en ambas poblaciones fue menor al valor que se encontró en una población de P. hartwegii en el Cofre de Perote, Veracruz (199) (Alba et al., 2003), quizás las condiciones de sitio o el tamaño de la población hayan favorecido para alcanzar un mayor número de semillas potenciales. El número de semillas potenciales es el límite máximo biológico de semillas que un cono puede producir (Bramlett et al., 1977); por lo tanto, Pinus hartwegii tiene mayor posibilidad de permanecer en su sitio de origen si presenta un alto número de semillas potenciales. El número de semillas potenciales mostró una correlación positiva moderada con la precipitación en los meses de julio y agosto $(r=0.643)$, temperatura media anual $(r=0.642)$ y temperatura media máxima del mes más caliente del año $(r=0.714)$; ésto significa que valores altos en estas variables ambientales influyeron moderadamente en el aumento de semillas potenciales de estróbilos de $P$. hartwegii en las altitudes donde estas variables fueron mayores. Por otro lado, con base también en el coeficiente de correlación ( $r=-0.614)$, una menor temperatura media mínima del mes más frío del año promovió un aumento en las semillas potenciales.

\section{Óvulos abortados}

El análisis de varianza no mostró diferencias significativas $(P=0.052)$ para el número de óvulos abortados en el año 1 en los conos de Pinus hartwegii entre las poblaciones y altitudes dentro poblaciones $(P=0.077)$, respectivamente; los valores promedio fueron 67 y 73 para el Nevado de Toluca y Monte Tláloc, respectivamente. La información sobre el número de óvulos abortados es nula sobre conos de esta especie en la literatura. Las poblaciones MT y NT presentaron 34.9 y $39.4 \%$ de óvulos abortados en el primer año, respectivamente, del total en cada población de semillas potenciales de P. hartwegii. El porcentaje de óvulos abortados fue menor que el porcentaje de 63 \% que se encontró en árboles en un huerto semillero de P. leiophylla Schiede ex Schltdl. Cham. (Gómez et al., 2010); sin embargo, el porcentaje de óvulos abortados en $P$. hartwegii en el presente estudio fue mayor que los valores de 14.6, 14.9 y $29 \%$ que se reportaron para P. durangensis Mart. (Bustamante-García et al., 2014), 
Cuadro 2. Medias de indicadores reproductivos de árboles de Pinus hartwegii en dos poblaciones del centro de México.

\begin{tabular}{|c|c|c|c|c|c|c|c|}
\hline \multirow[t]{2}{*}{ Indicadores reproductivos } & \multicolumn{4}{|c|}{$\begin{array}{l}\text { Monte Tláloc } \\
\text { Altitud (msnm) }\end{array}$} & \multicolumn{3}{|c|}{$\begin{array}{l}\text { Nevado de Toluca } \\
\text { Altitud (msnm) }\end{array}$} \\
\hline & 3600 & 3700 & 3800 & 4000 & 3900 & 4000 & 4100 \\
\hline Número de semillas potenciales & $205 b$ & $197 \mathrm{~b}$ & $222 a$ & $210 a b$ & $182 \mathrm{~cd}$ & $166 \mathrm{de}$ & $161 \mathrm{e}$ \\
\hline Número de óvulos abortados año 1 & $70 \mathrm{a}$ & $79 a$ & 71 a & $72 \mathrm{a}$ & $63 \mathrm{a}$ & $73 a$ & $64 \mathrm{a}$ \\
\hline Número de óvulos abortados año 2 & $7 c$ & $5 d$ & $11 \mathrm{~b}$ & $25 \mathrm{a}$ & $10 \mathrm{~b}$ & $13 b$ & $12 b$ \\
\hline Número de semillas vanas & $20 a$ & $14 b$ & $18 \mathrm{a}$ & $15 \mathrm{ab}$ & $6 c$ & $9 b$ & $12 b$ \\
\hline Número de semillas llenas & $107 \mathrm{~b}$ & $98 \mathrm{~b}$ & $120 \mathrm{a}$ & 91 bc & $101 b$ & $71 \mathrm{c}$ & $72 \mathrm{c}$ \\
\hline Peso promedio de una semilla (mg) & $14.5 \mathrm{e}$ & $15.6 d$ & $14.4 \mathrm{e}$ & $16.7 \mathrm{c}$ & $24.0 \mathrm{a}$ & $17.4 \mathrm{c}$ & $19.4 b$ \\
\hline Eficiencia reproductiva $\left(\mathrm{mg} \mathrm{g}^{-1}\right)$ & $75.5 b$ & $75.9 b$ & $83.7 \mathrm{a}$ & $76 a b$ & 86.9 a & $62.2 \mathrm{bc}$ & $55.1 \mathrm{c}$ \\
\hline Eficiencia producción de semilla (\%) & $52 a$ & $51 \mathrm{a}$ & $53 \mathrm{a}$ & $45 \mathrm{a}$ & $55 \mathrm{a}$ & $45 b$ & $43 b$ \\
\hline Índice de depresión endogámica & $0.15 a$ & $0.12 b$ & $0.14 \mathrm{a}$ & $0.14 a$ & $0.05 c$ & $0.11 b$ & $0.15 a$ \\
\hline
\end{tabular}

Medias con letras iguales en las hileras no son estadísticamente diferentes (LSmeans, $\mathrm{P} \leq 0.05$ ) para los indicadores que cumplieron con el supuesto de normalidad y La prueba Kruskal-Wallis $(P \leq 0.05)$ para aquellos que no cumplieron con el supuesto de normalidad.

P. engelmannii Carr. (Bustamante-García et al., 2012) y P. patula Schiede ex Schltdl. et Cham. (Mendoza-Hernández et al., 2018), respectivamente. Quizás el alto porcentaje de óvulos abortados en el primer año en P. hartwegii pudo deberse a una cantidad limitada de polen y asincrónica en su liberación y receptibilidad de los estróbilos femeninos. El número de óvulos abortados en el año 1 tuvo una correlación moderada negativa $(r=-0.607)$ con la temperatura promedio mínima del mes más frio; es decir, cuando la temperatura fue menor el número de óvulos abortados aumentó; sin embargo, la escasez de polen, auto incompatibilidad y fracaso de la fecundación son las causas principales que promueven un número alto de óvulos abortados en las escamas fértiles de los conos de especies del género Pinus (Owens y Fernando, 2007).

Se registraron diferencias significativas $(P<0.0001)$ para los óvulos abortados de $P$. hartwegii entre las poblaciones en el año 2; también, se encontraron diferencias entre altitudes $(P<0.0001)$ en el Monte Tláloc, pero no $(P=0.9944)$ entre altitudes en el Nevado de Toluca para este indicador reproductivo. El número de óvulos abortados en el año 2 fue cinco veces mayor a los 4000 msnm con respecto a esta variable a los 3700 msnm en el Monte Tláloc. Con base en los coeficientes de correlación, una menor temperatura media anual $(r=-0.785)$ y menor temperatura media en el mes más caliente $(r=-0.643)$ influyeron en forma moderada en el número de óvulos abortados; además, con base en los coeficientes de correlación, las heladas tempranas en otoño $(r=-0.750)$ y tardías en primavera $(r=0.774)$ provocaron en forma moderada un número mayor de óvulos abortados en el año 2. Probablemente estos factores ambientales influyeron en el desarrollo del cigoto, y como consecuencia, en la muerte del embrión.

El número de óvulos abortados en el año 2 representó el $6.3 \%$ del número de semillas potenciales de los conos de esta especie; este valor fue menor que los porcentajes (16.2 y 19.3) que Castilleja et al. (2016) encontraron en conos de $P$. rzedowskii, una especie que crece en poblaciones reducidas y $P$. ayacahuite var. veitchii.

\section{Semillas vanas}

Existieron diferencias significativas $(P<0.0001)$ entre poblaciones y entre altitudes $(P<0.0002)$ dentro de poblaciones de Pinus hartwegii para semillas vanas. Los valores promedios fueron 9 y 17 semillas vanas por cono en el NT y MT, respectivamente. El mayor número de semillas vanas se registró a los 3800 msnm en el MT, mientras que el menor valor se encontró en los 3900 msnm en el NT (Cuadro 2). El número promedio de semillas vanas representó el 5.3 y $8.1 \%$ en el NT y MT, respectivamente, respecto al número de semillas potenciales. Estos valores son bajos con respecto al número de semillas vanas que se encontró en otros estudios, siendo menores al porcentaje de $48.8 \%$ de semillas vanas que Iglesias et al. (2006) encontraron en conos de P. hartwegii en el Cofre de Perote, Veracruz. Castilleja et al. (2016) encontraron valores de 61.0 y $17.6 \%$ de semillas vanas en conos de P. rzedowskii y $P$. ayacahuite var. veitchii, con base en el número de semillas potenciales, respectivamente, mientras que Mendoza-Hernández et al. (2018) encontraron porcentajes de semillas vanas de15 a $17 \%$ en conos en un huerto semillero de P. patula en tres años de evaluación.

El porcentaje de semillas vanas en P. hartwegii en la 
presente investigación puede representar niveles bajos de autofecundación y cruzamiento entre individuos genéticamente emparentados, y éstos varían en las poblaciones, probablemente relacionados con presencia diferenciada de polen como consecuencia del número diferente de individuos presentes en cada población. La mayoría de las semillas vanas es producto del cruzamiento de individuos genéticamente emparentados donde hay mayor probabilidad de que genes letales formen genotipos homocigotos (Owens et al., 2005).

Una mayor precipitación influyó moderadamente en un aumento en el número de semillas vanas enjulio ( $r=0.607)$ y agosto ( $r=0.607$ ), temperatura media anual y temperatura media máxima ( $r=0.750)$ del mes más caliente; también, una menor temperatura mínima $(r=-0.607)$ en el mes más frío promovió un incremento moderado en el número de semillas vanas por cono.

\section{Semillas llenas}

Existieron diferencias significativas $(P \leq 0.0001)$ en el número de semillas llenas de Pinus hartwegii entre las poblaciones y entre altitudes dentro de ambas poblaciones. Los promedios fueron 82 y 104 semillas llenas en los conos que se recolectaron en el Nevado de Toluca y Monte Tláloc, respectivamente. El número de semillas llenas representó el 48.2 y 49.7 \% del potencial de semillas de los conos en NT y MT, respectivamente. El mayor número de semillas llenas se encontró a los 3800 msnm en MT, mientras que el mayor valor de este indicador reproductivo se encontró a los 3900 msnm en el NT (Cuadro 2). Quizás, una producción abundante de polen de un número elevado de individuos diferentes en la polinización y posterior fecundación favorecieron el desarrollo de la semilla, por lo que el número de semillas Ilenas fue alto. El porcentaje de semillas llenas en ambas poblaciones fue similar al porcentaje de semillas Ilenas (50 \%) que se encontró en el Parque Nacional Cofre de Perote (Iglesias et al., 2006); además, el porcentaje de semillas Ilenas de $P$. hartwegii en la presente investigación fue similar al porcentaje de semillas llenas (49\%) con respecto al número de semillas potenciales de conos de árboles de $P$. engelmannii y $P$. durangensis (Bustamante-García et al. 2012; 2014); sin embargo, el porcentaje de semillas llenas en conos de $P$. hartwegii fue superior al porcentaje de semillas Ilenas (17\%) que se registró en conos de árboles de P. leiophylla (Gómez et al., 2010).

Por otro lado, el porcentaje de semillas de P. hartwegii en el presente estudio fue ligeramente inferior al porcentaje de 50 a 58 \% de semillas que se encontró en conos en árboles en un huerto semillero de P. patula en tres años de evaluación (Mendoza-Hernández et al., 2018). Factores ambientales como abundancia de polen y sincronía en la maduración de los estróbilos masculinos y femeninos influyen en el número de semillas Ilenas; además, la tasa de cruzamiento entre árboles no emparentados y una tasa baja de autofecundación influyen en un número alto de semillas llenas por el hecho de que hay menor probabilidad de que alelos deletéreos formen homocigotos (Owens et al., 2005). Las semillas Ilenas son las únicas que pueden germinar y originar árboles jóvenes que reemplacen a los árboles maduros de una población. Con base en el coeficiente de correlación, la temperatura media anual $(r=$ 0.786) y la temperatura media máxima $(r=0.714)$ del mes más caliente influyeron moderadamente en el número de semillas llenas, mientras que la precipitación en los meses de septiembre y octubre $(r=-0.607)$ y las heladas tardías en primavera $(r=-0.667)$ influyeron negativamente en el número de semillas llenas.

\section{Peso de la semilla}

Existieron diferencias significativas $(P<0.0001)$ en el peso promedio de la semilla entre poblaciones y entre altitudes dentro de poblaciones de Pinus hartwegii. Los pesos promedio fueron de 15.3 y $20.3 \mathrm{mg}$ por semilla de esta especie en el Monte Tláloc y Nevado de Toluca, respectivamente. El peso mayor de la semilla se registró en conos que se recolectaron a 3900 msnm, mientras que el menor peso se encontró a los 4000 msnm en el NT (Cuadro 2). Por otro lado, el mayor peso de la semilla se encontró en los conos que se recolectaron a los 4000 msnm y el menor peso de la semilla se registró en los conos recolectados a los 3600 y 3800 msnm en el MT. Con base en el coeficiente de correlación, la temperatura media anual $(r=-0.679)$ y temperatura media máxima $(r$ $=-0.786$ ) del mes más caliente influyeron moderadamente en el peso de las semillas, por lo que a menor temperatura media anual y menor temperatura media máxima, el peso de la semilla es mayor.

Las semillas de mayor peso deben tener una mayor oportunidad de sobrevivir en las primeras fases de su ciclo de vida debido a un mayor contenido nutrimental en el tejido de reserva (Davidson et al., 1996). El peso de la semilla es útil para estimar el número de semillas por kg requerido en los programas de plantaciones. Se estimaron de 41,667 a 57,471 semillas $\mathrm{kg}^{-1}$ en El Nevado de Toluca, y de 59,880 a 69,444 semillas $\mathrm{kg}^{-1}$ en El Monte Tláloc. El peso promedio que se obtuvo para semilla de $P$. hartwegii (19.5 mg) en el Nevado de Toluca fue muy similar al peso de $21.0 \mathrm{mg}$ que reportaron Iglesias et al (2012) para esta especie en el Parque Nacional Cofre de Perote. 


\section{Eficiencia reproductiva}

Se detectaron diferencias significativas $(P<0.0004)$ entre las poblaciones y entre altitudes $(P<0.0001)$ dentro de poblaciones para eficiencia reproductiva. Los promedios fueron 68.1 y $77.8 \mathrm{mg} \mathrm{g}^{-1}$ para esta variable en El Nevado de Toluca y Monte Tláloc. El promedio fue 10.9 \% superior en la altitud de $3800 \mathrm{msnm}$ con respecto al promedio que se registró en la altitud de 3600 msnm en el MT, mientras que el promedio fue $57.7 \%$ superior en la altitud de 3900 msnm con respecto al promedio que se encontró en la altitud de 4100 msnm en el NT (Cuadro 2).

La eficiencia reproductiva tuvo una correlación baja $(-0.463<r<0.393)$ con las variables ambientales. No existe información sobre eficiencia reproductiva de la especie en la literatura. La eficiencia reproductiva es variable en especies del género Pinus, mientras que la eficiencia reproductiva en las estructuras reproductivas de árboles de P. hartwegii en la presente investigación presentaron valores superiores a $59 \mathrm{mg} \mathrm{g}^{-1}$, esta variable fue de $16 \mathrm{mg}$ $\mathrm{g}^{-1}$ en las estructuras reproductivas de P. leiophylla (Gómez et al, 2010). La eficiencia reproductiva es un indicador de la proporción de energía que un árbol dedica a la producción de semilla para la generación de nuevos individuos, por lo que refleja la proporción de energía que se almacena en las semillas (Mosseler et al., 2000).

\section{Eficiencia en la producción de semillas}

No existieron diferencias significativa $(P=0.1865)$ entre poblaciones de $P$. hartwegii, pero si entre altitudes $(P=0.0102)$ dentro de poblaciones para eficiencia en la producción de semilla. Los promedios fueron de 48 y $50 \%$ para este indicador reproductivo en el Nevado de Toluca y en Monte Tláloc, respectivamente. Los promedios mayores para eficiencia en la producción de semillas se encontraron en las altitudes de 3800 y 3900 en el MT y NT, respectivamente (Cuadro 2).

Con base en el coeficiente de correlación $(r=-0.829)$, las heladas tardías en primavera tuvieron un efecto negativo alto en la eficiencia en la producción de semillas de conos de $P$. hartwegii; por otro lado, la temperatura media anual $(r=0.679)$ y amplitud del periodo de heladas $(r=0.643)$ se asociaron de manera positiva y moderada en este indicador reproductivo de $P$. hartwegii. El valor de eficiencia en la producción de semilla en el presente estudio fue superior que el valor de $14 \%$ que se encontró para esta variable en una población en el Parque Nacional Cofre de Perote (Alba et al., 2003); sin embargo, el valor de eficiencia en la producción de semilla es variable en especies de Pinus. Una polinización insuficiente y baja viabilidad y vigor del polen pueden influir en la eficiencia en la producción de semillas por la presencia de alelos letales en individuos homocigóticos y daños biológicos (Bramlett et al., 1977). Las poblaciones aisladas y con un número reducidos de árboles tienen valores bajos en la eficiencia en la producción de semillas debido a que el polen es escaso y aumenta la probabilidad de autofecundación y cruzamiento entre árboles emparentados (Bramlett et al., 1977; Mosseler et al., 2000).

\section{Índice de depresión endogámica}

No existieron diferencias significativas $(P=0.2436)$ entre las poblaciones pero si entre altitudes $(P=0.0083$; $P=0.0001)$ en El Monte Tláloc y Nevado de Toluca, respectivamente para el índice de depresión endogámica en la producción de semillas de $P$. hartwegii en el presente estudio. El promedio fue de 0.14 y 0.10 para MT y NT, respectivamente. Los mayores índices de depresión endogámica en la producción de semilla se encontraron en las altitudes de 3600 y 4100 msnm en el MT y NT, respectivamente (Cuadro 2). El índice de depresión endogámica fue menor para P. hartwegii en el presente estudio que los valores de 0.48 y 0.50 que se encontraron en P. leiophylla (Gómez et al., 2010). Valores altos del índice de depresión endogámica están asociados con una alta tasa de cruzamiento entre individuos genéticamente emparentados (White et al., 2007). La endogamia implica un aumento en la frecuencia de individuos homocigóticos, los cuales pueden ser menos competitivos que los individuos heterocigóticos, particularmente en ambientes adversos, debido a la acción en estado homocigótico de alelos deletéreos o parcialmente deletéreos, fenómeno común en coníferas (Crnokrak y Barrett, 2002; Hartl y Clark, 2007).

\section{CONCLUSIONES}

Los indicadores reproductivos mostraron variación entre las poblaciones y altitudes dentro de poblaciones de Pinus hartwegii. En el Monte Tláloc se presentaron valores mayores para el número potencial de semillas, número de semillas llenas, eficiencia reproductiva y eficiencia en la producción de semillas, por lo que presenta características reproductivas que favorecen la permanencia de esta población. En el Nevado de Toluca se presentó el mayor valor en peso promedio de la semilla y un menor número de semillas vanas. Los indicadores reproductivos muestran mejor adaptación de esta especie a los 3800 msnm en el Monte Tláloc, y a los 3900 msnm en el nevado de Toluca. Los niveles de depresión endogámica relacionados con la producción de semillas fueron similares entre altitudes en ambas poblaciones. Las variables ambientales influyeron en los indicadores reproductivos en las poblaciones del Monte Tláloc y Nevado de Toluca, así como entre altitudes 
en cada una de las poblaciones de Pinus hartwegii.

\section{AGRADECIMIENTOS}

La primera autora agradece a CONACYT por la beca otorgada para realizar sus estudios de Maestría en Ciencias. También, se agradece al Colegio de Postgraduados por el financiamiento para la realización del presente trabajo a través del presupuesto AAA y proyecto aprobado en la convocatoria 2018 financiado por el Fideicomiso a las LGAC. Se agradece a los ejidos San Pablo Ixayoc, Tequexquinahuac, Nativitas, San Dieguito y San Miguel Tlaixpan del municipio de Texcoco por las facilidades brindadas para realizar la presente investigación.

\section{BIBLIOGRAFÍA}

Alba L. J., A. Aparicio R. y J. Márquez R. (2003) Potencial y eficiencia de producción de semillas de Pinus hartwegii Lindl. de dos poblaciones de México. Foresta Veracruzana 5:23-26.

Astudillo-Sánchez C. C., J. Villanueva-Díaz, A. R. Endara-Agramont, G. E. Nava-Bernal1 y M. Á. Gómez-Albores (2017) Influencia climática en el reclutamiento de Pinus hartwegii Lindl. del ecotono bosquepastizal alpino en Monte Tláloc, México. Agrociencia 51:105118.

Bramlett D. L., E. W. Belcher, G. L. De Barr, G. D. Hertel, R. P. Karrfalt, C. W. Lantz, ... and H. O. Yates (1977) Cone Analysis of Southern Pines - A Guidebook. General Technical Report SE-13. Southeastern Forest Experiment Station, Forest Service, U.S. Department of Agriculture. Asheville, North Carolina, USA. 32 p.

Burczyka J., A. Lewandowskib and W. Chalupka (2004) Local pollen dispersal and distant gene flow in Norway spruce (Picea abies [L.] Karst.). Forest Ecolgy and Management 197:39-48, http:// doi.org/10.1016/j.foreco.2004.05.003

Bustamante-García V., J. A. Prieto-Ruíz, A. Carrillo-Parra, R. Álvarez-Zagoya, H. González-Rodríguez and J. J. Corral-Rivas (2014) Seed production and quality of Pinus durangensis Mart., from seed areas and seed stands in Durango, Mexico. Pakistan Journal of Botany 46:1197-1202.

Bustamante-García V., J. Á. Prieto-Ruíz, E. Merlín-Bermudes, R. ÁlvarezZagoya, A. Carrillo-Parra y J. C. Hernández-Díaz (2012) Potencial y eficiencia de producción de semilla de Pinus engelmannii Carr., en tres rodales semilleros del estado de Durango, México. Madera y Bosques 18:7-21, https://doi.org/10.21829/ myb.2012.183355

Castilleja S. P., P. Delgado V., C. Sáenz-Romero and Y. Herrerías D. (2016) Reproductive success and inbreeding differ in fragmented populations of Pinus rzedowskii and Pinus ayacahuite var. veitchii, two endemic Mexican pines under threat. Forests 7:178, http://doi.org/10.3390/f7080178

Crnokrak P. and S. C. H. Barrett (2002) Perspective: purging the genetic load: a review of the experimental evidence. Evolution 56:23472358, https://doi.org/10.1111/j.0014-3820.2002.tb00160.x
Davidson R. H., D. G. W. Edwards, O. Sziklai and Y. A. El-Kassaby (1996) Genetic variation in germination parameters among populations of pacific silver fir populations. Silvae Genetica 45:165-171.

Endara-Agramont A. R., R. Calderón-Contreras, G. Nava-Bernal and S. Franco-Maass (2013) Analysis of fragmentation processes in high-mountain forests of the centre of Mexico. American Journal of Plant Sciences 4:697-704, http://doi.org/10.4236/ ajps.2013.43A088

Gómez J. D. M., C. Ramírez H., J. Jasso M. y J. López U. (2010) Variación en características reproductivas y germinación de semillas de Pinus leiophylla Schiede ex Schltdl. \& Cham. Revista Fitotecnia Mexicana 33:297-304, https://doi.org/10.35196/ rfm.2010.4.297

Hartl D. L. and A. G. Clark (2007) Principles of Population Genetics. 4th ed. Sinauer Associates. Sunderland, Massachusetts, USA. $652 \mathrm{p}$

Iglesias L., I. Mora y J. L. Casas (2006) Morfometría, viabilidad y variabilidad de las semillas de la población de Pinus hartwegii del Cofre de Perote, Veracruz, México. Cuadernos de Biodiversidad 19:1418, http://doi.org/10.14198/cdbio.2006.19.03

Iglesias L. G., L. Y. Solís-Ramos y H. Viveros-Viveros (2012) Variación morfométrica en dos poblaciones naturales de Pinus hartwegii Lindl. del estado de Veracruz. Phyton 81:239-246.

Mendoza-Hernández N. B, C. Ramírez-Herrera, J. López-Upton, V. ReyesHernández y P. A. López (2018) Variación de características reproductivas de árboles de Pinus patula en un huerto semillero sexual. Agrociencia 52:279-291.

Mosseler A., J. E. Major, J. D. Simpson, B. Daigle, K. Lange, Y. S. Park and 0. P. Rajora (2000) Indicators of population viability in red spruce, Picea rubens. I. Reproductive traits and fecundity. Canadian Journal of Botany 78:928-940, https://doi.org/10.1139/b00065

Owens J. N., J. Bennett and S. L'Hirondelle (2005) Pollination and cone morphology affect cone and seed production in lodgepole pine seed orchards. Canadian Journal of Forest Research 35:383 400, https://doi.org/10.1139/x04-176

Owens J. N. and D. D. Fernando (2007) Pollination and seed production in western white pine. Canadian Journal of Forest Research 37:260-275, https://doi.org/10.1139/X06-220

Perry J. P. (1991) The Pines of Mexico and Central America. Timber Press. Portland, Oregon, USA. $231 p$

Rajora O. P., M. H. Rahman, G. P. Buchert and B. P. Dancik (2000) Microsatellite DNA analysis of genetic effects of harvesting in old-growth eastern white pine (Pinus strobus) in Ontario, Canada. Molecular Ecology 9:339-348, https://doi.org/10.1046/j.1365294x.2000.00886.x

Rehfeldt G. E. (2006) A spline model of climate for the Western United States. General Technical Report RMRS-GTR-165. Rocky Mountain Research Station, USDA Forest Service, Fort Collins, Colorado, USA. 21 p, https://doi.org/10.2737/RMRS-GTR-165

SAS Institute (2012) Guide for SAS ${ }^{\circledR} 9.4$ Foundation for Microsoft Windows for x64. SAS Institute Inc. Cary, North Carolina, USA $47 \mathrm{p}$.

Villers-Ruiz L. e I. Trejo-Vázquez (2004) Evaluación de la vulnerabilidad en los ecosistemas forestales. In: Cambio Climático: Una Visión desde México. J. Martínez y A. Fernández-Bremauntz (comps.) Secretaría de Medio Ambiente y Recursos Naturales-Instituto Nacional de Ecología. México D.F. pp:239-254.

White T. L., W. T. Adams and D. B. Neale (2007) Forest Genetics. CAB International. London, UK. $682 \mathrm{p}$. 